\title{
THE INFLUENCE OF TECHNOLOGICAL ADVANCEMENT ON THE FUTURE DEVELOPMENT OF DESIGN TEACHING
}

\author{
Yong L* \\ Beijing Institute of Technology, Zhuhai, China \\ Bangkok Thonburi University, Bangkok, Thailand
}

\begin{abstract}
The study of the development process of China's information education can find that the technological development represented by information technology has had a positive impact on classroom teaching. Design is an applied discipline. In design teaching, technological progress directly affects discipline development, teaching curriculum design, and classroom teaching management. The evolution of teaching content design is the need to continuously adapt to the changes in the new technological environment, and the design of the teaching process and teaching content should pay more attention to the future. The development of education in the future is an issue that we need to study. As the development process of online education, the development of design disciplines also shows that design and technological development are in an integrated relationship, and the influence of technological progress on design education is an interdisciplinary influence. Teaching content design is not only the application of new technology, but also the process of self-improvement, iteration and progress of design education, and ultimately serves the main body of teaching, teachers and students.
\end{abstract}

Keywords: Education; Technological; Future Education

\section{Introduction}

It is found from the 3 phases of China informationized education development that new technology development represented by $5 \mathrm{G}$ information technology has a positive effect on class education.Like online education, education development of design has gone through the same development history with technology progress. Education technology process has a interdisciplinary effect on design education. Enrichment and changes of education resources, optimization of education process and progress of education method have become a trend and phenomenon.Education content is not only designed to apply new technology, but also self-improving, iteration and progress for each discipline represented by design education and finally serving for education subject, as well as teacher and students. Good education ecological construction shall make reasonable use of technology development advantages to promote overall development people in the education industry in the future.

Due to the influence of COVID-19, in the past two years of practical teaching, we have carried out nationwide network teaching, and our technology application ability has been greatly improved in a short period of time. Recognizing the importance of technological progress and improving the ability to apply technology to future education. 


\section{Development of China remote education}

The first remote education is correspondence education, which began at the beginning of the $20^{\text {th }}$ century earliest, It mainly adopted the traditional method of mailing reading materials printed. Some problems such as low attendance rate, backward technology means and unwarrantable self-study quality finally made it fall into a decline.

The second remote education is radio and television education arisen in 1980s, which is a remote education form supported by technology such as radio, television, video, audio recording and other individual media. Theoretical education and practice exploration have enriched China remote education construction, which lays a solid foundation of spanning to the third remote education.

The third is the modern remote education based on information and internet technology in 1990s. The third model remote education is featured by being guided by the government for development and innovation.In 2007, China government work report wrote, "Develop remote education and adult education and build a leaning society of learning for all and life-long learning." Zhou Ji, the the Ministry of Education leader, said, "Application to information technology is used as the new means of improving education quality".

According to data from the Chinese government website,In 2020, affected by COVID-19, and promoted by China Policy of "classes suspended but learning continues", 0.282 billion of internal student throughout China turned to learn online in the stage. As of June 2020, the online education users of our country was up to 0.381 billion. Informationized process of education speeds up obviously, and online education users amount hits a new high in the history, online education industry is embracing a high developing period.

\section{Education development review in terms of technology}

Education technology has a closer and closer relationship with media technology:Progress of media technology provides conditions and supports for development of education technology; Development of education technology promotes birth of new media technology and media form in turn.The technology of these three layers is unseparated and interactional from each other. During different development phase of education technology, the three layers have different emphasis. With the development of education technology, the overall integration will become stronger and stronger. Education technology with an aim of optimizing education effect will be sure to pay more and more attention to realizing technology such as education design, visual feeling and immersion experience. 


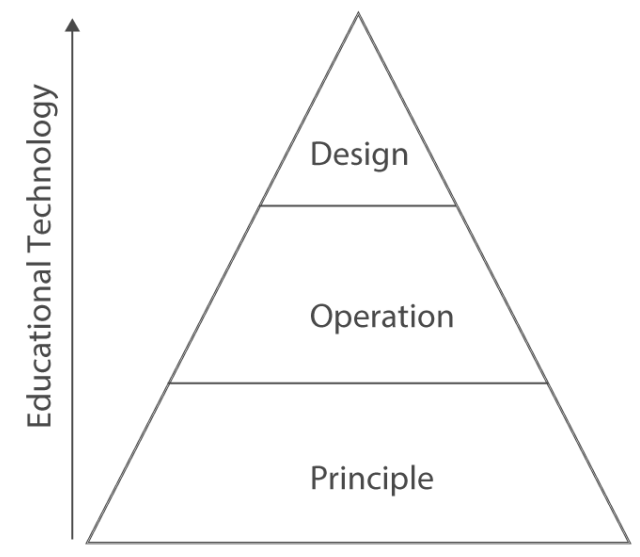

Figure 1: Educational technology consists of three levels to technology: Principle Technology, Operation Technology, Design Technology. The presentation of design results with good visual effects and user experience reflects the progress of technology

\section{Online education technology is promoting formation of intellectual education ecology}

In China, intellectual technology represented by AI, big data, cloud computing, LOT and virtual reality is promoting transformation of the whole society. More and more people are ware that intellectual technology is the basic feature of future education and brand-new intellectual education ecology is being formed. China has set it a China strategy to develop 5G and is speeding up formation, $\mathrm{R} \& \mathrm{D}$ and application of $5 \mathrm{G}$ standard.

The integrated development of intelligent technology and education promotes the integration of physical and virtual learning environment, speeds up the integration of online and offline education, and makes personalized, situational and data-driven learning the norm, so as to establish an educational ecology of man-machine interaction.

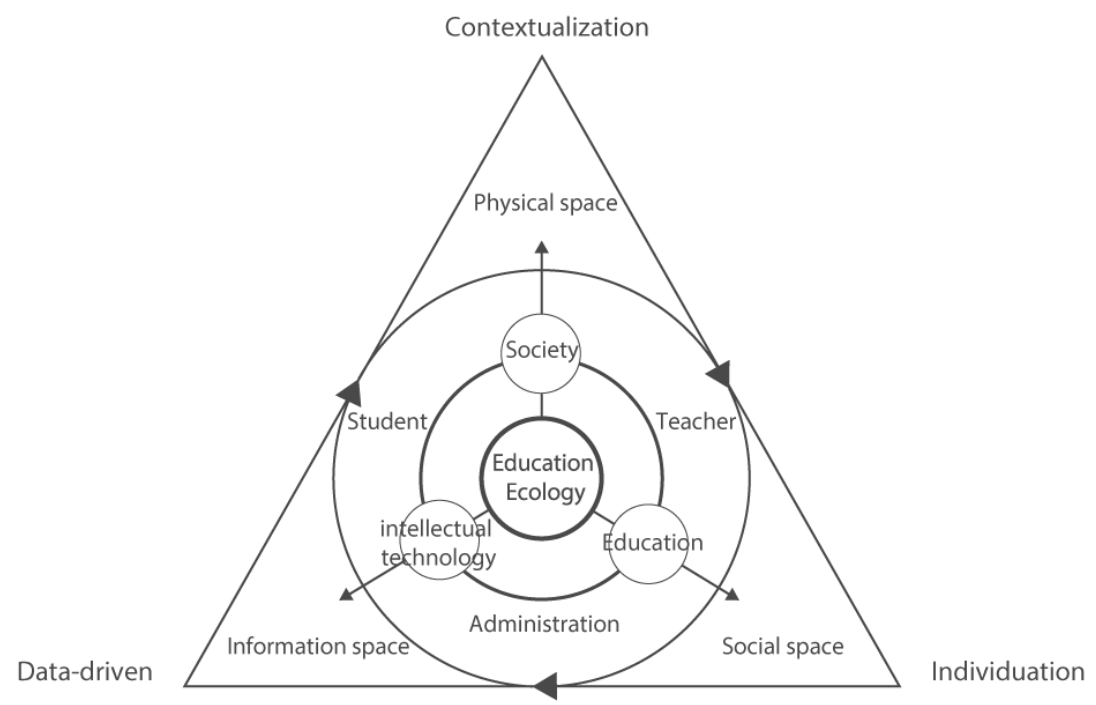

Figure 2: Intelligent Education Ecology supported by $5 G$ and smart technologies. Intelligent technology will make the education ecology present the characteristics of contextualization, individualization and data-driven, which will help to realize that each education subject can obtain personalized support in different situations. The elements are interconnected and interacted with each other, and the behavior of each educational subject has changed 
Data Explanation on the Website of the Ministry of Education of China, Since 2017, the Ministry of Education has selected and identified national first-class courses, including 1875 online courses, 728 virtual simulation experimental courses and 868 online and offline mixed courses, which plays a significant exemplary role in the development of the construction and application of MOOC.

In 2020, after the outbreak of COVID-19, China's Ministry of Education organized 37 online course platforms and technology platforms with good foundation and strength to open 41000 online courses, such as MOOC and virtual simulation courses free of charge to colleges and universities across the country. More than 110 social and university online course platforms actively participated, which ensured the operation of online courses in colleges and universities across the country effectively.

Traditional education and training institutions are gradually expanding their online business. The potential of the online education industry continues to attract the layout of large Internet companies. In 2020, the online education industry got good development opportunities and attracted many institutions and capital. Data show that there were 82,000 new online education enterprises in China from January to October 2020, accounting for $17.3 \%$ of the total education industry. The online education industry disclosed a total of 89 financing incidents from January to the end of November 2020, with a total financing amount of about 38.8 billion yuan.

\section{Development of design education in new technology changes}

Design is a crossed interdisciplinary subject, which requires designers to integrate, analyze and judge design information resources from many aspects. Learning method is bound to be transformed due to technology requirement. The information society has put forward unprecedented requirements for designers' ability literacy, especially information literacy. A student with information literacy can effectively determine information, effectively critically evaluate information, accurately and creatively utilize information.

\section{Enrichment of teaching resources and construction of teaching content:}

The advantage of 5G communication technology of "the Internet of everything" makes the traditional classroom space expand infinitely, and the rich internet teaching resources can be introduced into the classroom. Meanwhile, originally independent teaching units can access massive network teaching resources, and the rich advantages of teaching resources are demonstrated thereby.

The data show that the online teaching platform represented by "Ke.qq.com" remained hot for the design and creation courses during the outbreak of COVID-19 in 2020, among which graphic design, environmental art and design software were the most popular. and users were willing to pay for these courses.

\section{Optimization of teaching design:}

Traditional technology model limits students to an limited teaching space, interaction and discussion between teachers and students are relatively closed. While in 5G times, teaching and learning are not limited by time and space and have more freedom. Teachers can communicate and interact with students conveniently so that the individual features of students can be further released. 
To change students' feeling to content, experiential teaching should be the focus, to present characters, pictures, audios, and videos and other design factors in a brand new technology method in front of students.

To change students' knowledge to content and function, so that students can practice these contents conscientiously and enter specific learning atmosphere, and have deeper understanding for teaching content and function.

\section{Progress of teaching method:}

If $\mathrm{VR}$ or $\mathrm{AR}$ technology is integrated into class, students will be under a more real teaching environment and immersed into virtual real scene.

For example, the design virtual simulation experiment course "Optical Media Design Virtual Simulation Laboratory Teaching Project" of Renmin University of China is aimed at realizing "doing experiments online" through the deep integration of information technology, intelligent technology and experimental teaching. The project ensures the variety of lights and the richness of the simulated scene.

\section{Change of students employment objective:}

Explore employment market guided by employment. Educators must have a clear idea of the ability and level that students should achieve when they graduate, and then seek to design an appropriate educational structure to ensure that students achieve these expected goals.

Correlate the investigation on the development of enterprises related to discipline construction and specialty construction in teaching with big data analysis;

Highlight the core of post skills training in the teaching process, collect industry development and change data regularly, and build a more prominent teaching guarantee system for employment preparation;

Teachers should be well-prepared for the professional construction reform that meets the requirements of employment objectives, so as to make students in a teaching environment that is more conducive to employment exploration.

With promotion and popularization of new technology, adjustment to traditional teaching model is an inevitable trend. The change of this adjustment trend requires to adapt to enriched changing process of teaching resources, optimize teaching links and promote the progress of teaching methods.

However, in traditional teaching, students and teachers get along with each other day and night, influence and promote each other. This kind of humanistic environment cannot be replaced by online education. Teachers need to be deeply aware of the changes produced by technology and adjust teaching thinking in combination with the actual situation in the teaching work to provide students with a space more conducive to their knowledge growth and ability progress with the help of technological innovation. 


\section{Conclusion}

Online education content represented by design online education is just a part of overall education ecology. Similarities and differences co-exist between online education and traditional education. New technology progress has brought revolutionary changes to progress of education technology and promoted transformation and creation of tradition education form. However, education is to cultivate people, technology needs to serve for technology subject. Good teaching ecology construction should make reasonable use of technology development advantages and promote overall development of people in the education industry in future.

\section{References}

(2021).China internet industry development review in 2020. Internet World(01),16-19. doi:CNKI:SUN:HLWT.0.2021-01-005.

Gangshan F. (2005).Research on the Development Track of Educational Technology. e-Education Research(09),22-26. doi:CNKI:SUN:DHJY.0.2005-09-005.

Ronghuai H, Wei Z, Jing D, Feipeng S, Huanhuan W, Haijun Z \& Dejian L. (2019). Three basic computing problems for intelligent education. Open Education Research (05), 11-22. doi: 10.13966/j.cnki. kfjyyj.2019.05.002.

Junxia Z , Junfeng Y \& Rong huai H.(2020).A New Opportunities and Challenges for Education in the 5G Age. e-Education Research(12),1-8. doi:CNKI:SUN:ZDJY.0.2020-12-001.

The $47^{\text {th }}$ Statistical Report on Internet Development in China released by CNNIC. (2021,February 3). Retrieved from http://www.gov.cn/xinwen/2021-02/03/content_5584518.htm

The first batch of state-level first-class undergraduate courses were announced, Ministry of education higher education department responsible person answers the reporter to ask . (2020, December 20). Retrieved from http://www.gov.cn/zhengce/2020-12/01/content_5566135.htm 